\title{
ADVANCED MITRAL STENOSIS AT THREE YEARS OLD
}

\author{
BY
}

\section{R. SLEIGH JOHNSON AND DAVID LEWES}

From the Southend General Hospital

Received October 28, 1944

Although rheumatic infection in infancy has been recorded frequently, chronic (healed) rheumatic endocarditis with established mitral stenosis, presenting without manifestations of acute or active carditis, must be exceptional. The following case of a male infant falls into this latter category.

\section{CASE History}

The patient was first seen on May 12,1942, at the age of 2 years 8 months. The mother stated that for the previous two weeks he had suffered from bouts of spasmodic coughing, accompanied by blueness of the lips and hands, and followed by vomiting and much shortness of breath. In all he had had six such attacks and had become progressively more short of breath, not only during the attacks, but also when at complete rest. His activities had, of his own accord, become steadily curtailed during this period, so that he avoided all forms of exertion, and only with persuasion could he be induced to walk. Further enquiry revealed that the infant had appeared normal in every way, from birth until the age of 21 months, when he began to walk. At this time shortness of breath on exertion was noticed, and the abdomen became unduly prominent. Henceforth development was retarded and he grew but slowly. He tended to be sluggish in habits, avoiding all exertion that might induce breathlessness; otherwise he remained well. Until the present illness this shortness of breath and abdominal distension were not progressive. He had had none of the acute specific fevers, nor was any history of intercurrent illness, such as tonsillitis or sore throat, obtained. Close questioning failed to elicit any history of past rheumatic infection either in the patient or the parents. The mother was a healthy woman of 28 years; she had one other child, aged 2 years. Both pregnancies had been normal and there had been no miscarriages. The father was healthy and had been graded A.1 by a medical board.

On examination the infant lay listless, dyspnœic, and reluctant to move. Undeveloped physically and mentally for his age, the anterior fontanelle was widely open. The face was bloated and pale, with cyanosis of the lips; the extremities felt cold and were also of a dusky hue. The temperature was raised to $101 \cdot 4^{\circ} \mathrm{F}$. and the pulse rate to 130 ; the rhythm was regular. The apex beat was diffuse but forcible and displaced to the left. No thrill was felt. On auscultation a loud and long grating systolic murmur, maximal in the mitral area, was heard over the præcordium, while a to-and-fro rough and moderately loud murmur was heard in the triscupid area. Examination of the lungs revealed impairment of percussion and diminished air entry at the left base; elsewhere the breath sounds were harsh. The abdomen was notably distended and the umbilicus everted. There was firm hepatic enlargement of four fingers' breadth, but this was not tender, and no ascites was demonstrated.

Since rheumatic heart disease was considered unlikely in one so young, a tentative diagnosis of heart failure, due to congenital heart disease and complicated by whooping cough, was made. The patient was transferred to the Borough Isolation Hospital for further observation and treatment. There the provisional diagnosis of pertussis was confirmed, while the comment on the heart recorded on admission was that "a markedly roughened first mitral sound, resembling an adult presystolic murmur was heard." Shortly after admission overt signs of bronchopneumonia developed. Response to treatment, which included continuous oxygen and chemotherapy, was satisfactory and in spite of a relapse of pneumonia twelve days later the infant was discharged considerably improved, although still breathless, three weeks after admission. 
On July 21 , nine weeks after being first seen, the patient was again referred to the Southend General Hospital and admitted, having suddenly become gravely ill with rapidly increasing shortness of breath, abdominal distension, and swelling of the legs. On examination there was severe dyspnœa with cyanosis and much swelling of the face and eyelids. Edema was generalized; the abdomen was considerably more distended than at the first examination, but ascites again could not be detected. Moist sounds were heard at both lung bases, with diminished air entry and impaired percussion note over the left lower lobe. The pulse continued to remain regular; nor was there any significant alteration in the character of the heart murmurs. X-ray of the chest (Fig. 1) showed considerable

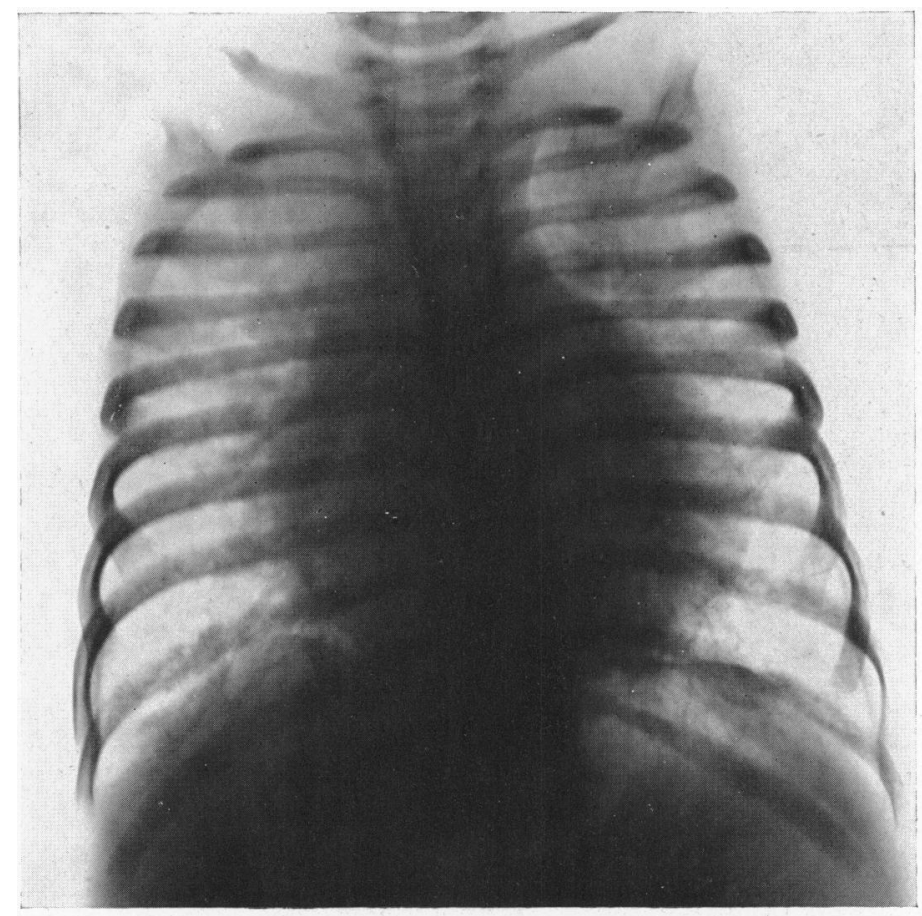

FIG. 1.-Radiogram of chest, showing gross globular enlargement of the heart shadow and marked hilar congestion $(27 / 7 / 42)$.

enlargement of the heart shadow, strikingly globular in outline, and gross hilar congestion. The Wassermann reaction was negative.

Death occurred unexpectedly and rapidly, two days after admission. Without warning, the patient vomited with inhalation of the vomitus. Deep cyanosis with urgent dyspnœa immediately ensued, and in spite of prompt treatment by aspiration-bronchoscopy death took place in twenty minutes.

\section{Autopsy Findings}

The body was that of an undeveloped but well-nourished infant, swollen by generalized œdema which was most pronounced in the lower extremities, back, and face. Bilateral clear pleural effusions, each of 300 c.c. $(10$ oz.), were present, and both lungs which showed partial pressure collapse were congested and very odematous. There were numerous subpleural Tardieu spots.

The heart (Fig. 2) was considerably enlarged and dilated, weighing $98 \mathrm{~g}$. (normal average weight at 2 years 10 months being $60 \mathrm{~g}$. according to Coppoletta and Wolbach, 1933). There were scattered petechial hæmorrhages beneath visceral and parietal pericardium; the pericardial fluid was normal in amount and colour. No trace of old or recent pericarditis was present. The left auricle was greatly dilated and hypertrophied ( $3 \mathrm{~mm}$. thickness), the endocardium on the posterior wall being thickened and crinkled over an area of $2 \mathrm{~cm} . \times 1 \mathrm{~cm}$. The mitral ring was contracted and narrowed to $1.5 \mathrm{~cm}$. diameter, while the valve cusps were rigid, deformed, and grossly thickened by dense fibrosis without calcification; their margins were fused together except for a narrow slit $1 \mathrm{~cm}$. in length, which was placed at the centre 


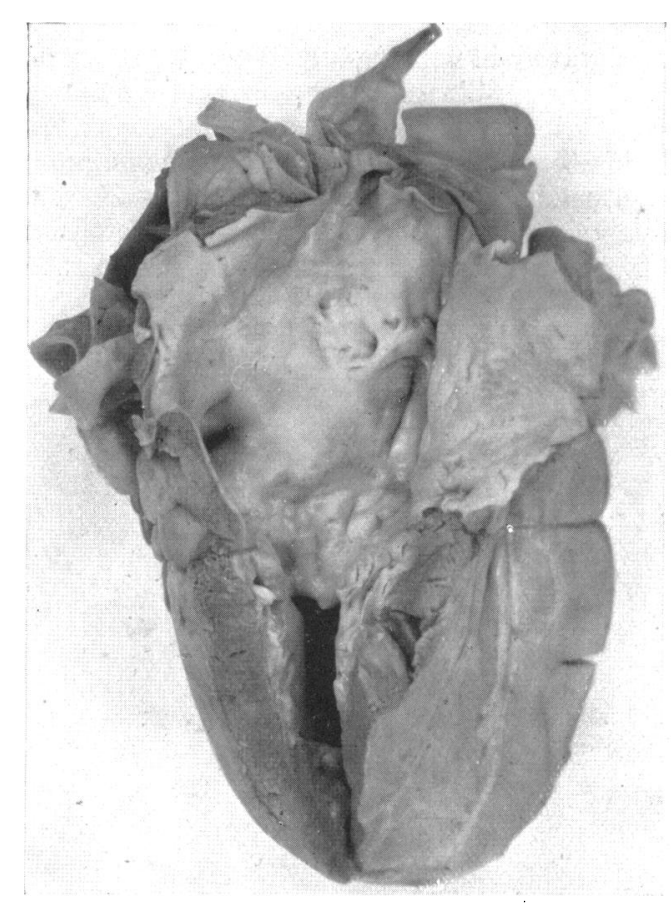

A

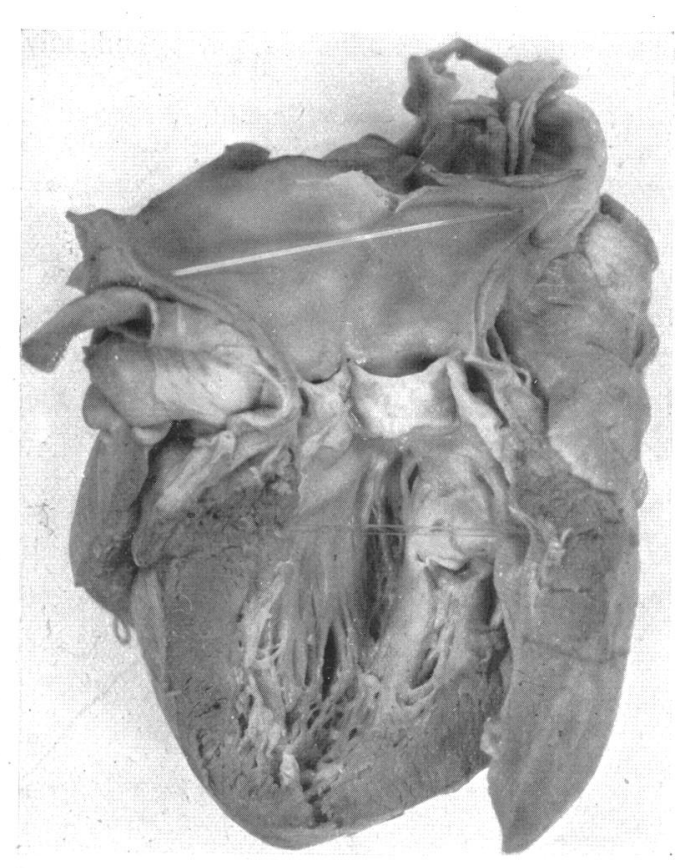

B

Fig. 2.-Photographs of the heart.

(A) Shows dilatation of the left auricle, deformity and thickening of the mitral cusps, and narrowing of the mitral ring.

(B) Shows thickening and deformity of the aortic valve cusps, with hypertrophy of the left ventricle, and narrowing of the mitral valve.

of a diaphragm of cartilaginous consistence (" button-hole" stenosis). The chordæ tendineæ were so shortened and thickened as to be unrecognizable. The left ventricle showed considerable hypertrophy ( $9 \mathrm{~mm}$. thickness) with some dilatation. On section the myocardium appeared normal throughout. The aortic incompetence test was positive, while the aortic valve cusps were rigid, deformed, and partly adherent to each other causing stenosis. The right ventricle and right auricle were dilated and the former was hypertrophied $(5 \mathrm{~mm}$. thickness). The tricuspid and pulmonary valves were normal. The foramen ovale was closed, and no patency of the interventricular septum nor any of the recognized forms of congenital morbus cordis was present.

Moderate ascites was present. The liver was hard, slightly shrunken, and the capsule wrinkled, due to recent reduction in size of the organ. On section the parenchyma showed advanced back-pressure changes with secondary fatty degeneration. The spleen and kidneys were firm and congested; the other organs were normal.

Microscopical Examination (Dr. J. R.. Gilmour). " A portion of cardiac valve (posterior mitral) shows fibrous thickening and vascularization of cusp (chronic rheumatic endocarditis). There is thickening of the aortic cusp by increase of collagen and spindle fibroblasts; no vessels or inflammatory cells seen in the cusp; a small fragment of attached myocardium is normal, but a little mural endocardium over it, immediately below the valve, is thickened by increase of collagen, fibroblasts, and capillaries. The picture is typical of chronic rheumatic aortic and mitral endocarditis. There is no other endocarditis known that would produce similar scarring. The right ventricular and left auricular myocardium shows hypertrophy; there is no evidence of healed or active rheumatic myocarditis. The liver shows fatty degeneration and central chronic passive congestion." 
Discussion

The incidence of rheumatic infection in the first three years of life represents approximately 1 per cent of the total incidence throughout all age groups. The vast majority of this early group occur during the third year, while rheumatic infection before the age of two years is rare. Thus Still (1909) in a series of 1027 cases of rheumatic fever in children found none under two years and eight cases between the second and third year; i.e. less than 0.8 per cent. Among 364 cases of rheumatic arthritis Findlay (1931) recorded none under two years and three cases under three years, while in 457 cases of rheumatic carditis he found two cases occurring in the first two years and four between the second and third year. Finally, McIntosh and Wood (1935) quote collected figures of 2884 cases of rheumatic infection at all ages in which 40 , or 1.3 per cent, occurred in the first three years of life.

Although rheumatic infection is uncommon in infancy, it is nearly always accompanied by a severe degree of cardiac involvement, usually of an acute type. McIntosh and Wood (1935) in their series of 24 cases of rheumatic infection in the first three years, found clinical or post-mortem evidence of cardiac involvement in 22, or 92 per cent. However, chronic rheumatic endocarditis with advanced mitral stenosis and congestive heart failure, presenting without manifestations of acute rheumatism and without post-mortem or microscopical evidence of active rheumatic carditis, must be very rare before the third year. Two cases comparable to the present one have been reported by Day (1932) and by McIntosh and Wood (1935). Day's case concerned a female, dying at the age of 24 months; following an attack of " influenza " and otitis media at 10 months, she failed to make progress, and developed heart failure with cardiac enlargement, œdema with pleural effusion, and marked hepatic enlargement at 20 months. At necropsy, the mitral valve was greatly thickened and the orifice reduced to a narrow slit: there was no microscopical evidence of active carditis. McIntosh's and Wood's case (No. 6 in their series) was that of a male, aged 2 years 10 months, who developed bronchopneumonia at 21 months and attacks of generalized œdema with liver enlargement at 26 and 31 months respectively. Death occurred 3 months after the second attack following recurrence of pneumonia. At necropsy the heart weighed $196 \mathrm{~g}$; the mitral cusps were greatly thickened and nodular with fused verrucæ along the free margins. Microscopic examination showed fibrosis of the myocardium with occasional interstitial accumulation of lymphocytes. The valvular lesions suggested a healed rheumatic process, the authors stating these findings to be unique in their experience. Eigen (1938) and Quinlan (1942) have each reported a case of chronic rheumatic carditis with mitral stenosis at 2 years 8 months. In both instances, however, microscopical examination showed an acute imposed upon chronic endocarditis as distinct from the pure chronic or healed rheumatic process, thus differing in an important respect from our own case and those described above.

It is not surprising that rheumatic carditis in infancy is almost invariably encountered as an acute or active condition and so rarely in the chronic and healed form; for the time factor is against an extensive cardiac lesion becoming healed before the third year, while the ability of the heart muscle to compensate in the young, even for the grossest valvular defect, needs no emphasis, and death from congestive failure alone and opportunities for autopsy are correspondingly rare.

\section{The Possibility of INTRA-Uterine Rheumatism}

The striking absence of any acute illness prior to the first attendance, the long-standing history of symptoms of heart failure, and the extent of the valvular lesions found at autopsy, all point to an established cardiac lesion with heart failure even before the age of two years, besides making an apparently strong case for intra-uterine rheumatic infection. Although fœtal endocarditis is a possibility that cannot be disproved, there is much evidence that can be marshalled against it in our case. A completely normal pregnancy in the mother and 
an absence of any history of rheumatic infection during this period or at any other time in either parent, is strongly opposed to an invocation of intra-uterine rheumatism.

A study of the reported cases of intra-uterine rheumatism reveals that the evidence on which such a diagnosis is based is circumstantial and rests on two observed facts: active rheumatic infection during pregnancy, and similar manifestations in the offspring immediately following or in the first few weeks after birth. Two of the most convincing cases reported are those of Kissane and Koons (1933) and of Ferguson (1893). In Kissane's and Koon's case the mother had had recurrent rheumatic fever since the age of 12 years; a cardiac lesion had been noticed at 20 years, and she had suffered from active rheumatic fever with swollen joints throughout her entire pregnancy at the age of 25 years. The infant was born with red painful joints and 30 hours after birth abnormal cardiac sounds were heard. Joint symptoms and dyspnœa persisted for six months. Death occurred at 9 years when panvalvulitis and gross mitral stenosis was proved at autopsy. Ferguson's case developed acute rheumatic fever with joint involvement 10 days after birth, the mother having suffered from severe rheumatic fever from the second month of pregnancy.

Whereas much attention is paid, and even undue weight attached, to a past history of rheumatic fever in the diagnosis of mitral disease, many patients with established rheumatic endocarditis tender no such history. Conversely, a large number and perhaps the majority who give a history of rheumatic infection in the past, have no demonstrable cardiac lesion at the time of examination. It is frequently the case in the adult that the most extreme, that is the most chronic and insidously progressive cases of mitral stenosis are those that give no history of acute rheumatic fever nor chorea, but in contra-distinction develop a slow relentless sclerosis of the mitral valve structures without acute endocardial changes. Tight " buttonhole" stenosis with narrowing of the mitral ring is the relatively outstanding feature in such cases, unrevealed in some instances until the onset of failure, in contrast with the greater tendency to pancarditis and deformity with beading of the valve cusps in cases with a history of recurrent acute rheumatism, the form seen most commonly in children and young adults. It is the former or "adult" type of lesion that is portrayed by our own case. The most likely explanation, therefore, which would account for the extreme degree of mitral stenosis noted in the present case, is that the rheumatic infection was acquired, developing some time after birth as a pure cardiac lesion, and that the patient entered as a very junior member that large group of older people whose hearts are silently but permanently damaged by one of the subtlest and most incapacitating diseases known to medicine.

\section{SUMMARY}

A case of chronic (healed) rheumatic endocarditis with advanced mitral stenosis in an infant aged two years and ten months is reported, together with the autopsy findings.

We wish to thank Dr. J. R. Gilmour for permission to record the morbid histology findings in this case, and Dr. R. B. Christie for clinical information while the patient was under his care.

\section{REFERENCES}

Coppoletta, J. M., and Wolbach, S. B. (1933). Amer. J. Path., 9, 55.

Day, H. B. (1932). Lancet, 1, 1144.

Eigen, L. A. (1938). Amer. Heart J., 16, 363.

Ferguson, J. H. (1893). Edinburgh Hosp. Rep., 1, 608.

Findlay, L. (1931). The Rheumatic Infections in Childhood. N.Y., Longmans, Green and Co.

Kissane, R. W., and Koons, R. A. (1933). Arch. intern. Med., 52, 905.

McIntosh, R., and Wood, C. L. (1935). Amer. J. Dis. Child., 49, 835.

Quinlan, J. T. (1942). Brit. med. J., 2, 695.

Still, G. F. (1909). Common Disorders and Diseases of Childhood. N.Y., Oxford University Press. 